\section{Resumen}

El Bicentenario es un suceso capaz de desplegar asertos y versiones inusitadas del sueño independentista; en este artículo el autor utiliza la imagen del héroe para repensar la pedagogía, la construcción del sujeto maestro y su discípulo. El periplo seleccionado pasa por autores y obras románticas de primer orden: Jean Jacques Rousseau, William Shakespeare, Daniel Defoe y Simón Rodríguez, el factor común entre los autores es el carácter romántico propio de aquellos discípulos creados a imagen y semejanza de sus maestros: Calibán, Robinson Crusoe, Emilio y Simón Bolívar. Un segundo momento acude a obras de José Enrique Rodó y Roberto Fernández Retamar para configurar metafóricamente la subjetividad latinoamericana.

\section{Palabras Clave}

Héroe, pedagogía, maestro, discípulo, romanticismo, modernidad, subjetividad.

\section{Abstract}

The Bicentennial is an event capable of displaying assertions and unusual versions of the independence dream, in this article the author uses the hero's image to rethink pedagogy, the construction of the subject teacher and his disciple. The selected tour passes by authors and first-rate romantic works: Jean Jacques Rousseau, William Shakespeare, Daniel Defoe and Simon Rodriguez, the common factor among these authors is the romantic character of those disciples, created in the image and likeness of their masters: Caliban, Robinson Crusoe, Emilio and Simon Bolívar. A second point goes to the works of Jose Enrique Rodo and Roberto Fernandez Retamar to metaphorically configure the Latin American subjectivity.

\section{Keywords}

Hero, pedagogy, teacher, disciple, romanticism, modern age, subjectivity. 


\title{
Robinson Crusoe, Rousseau y Simón Rodríguez: pedagogos de la modernidad ${ }^{1}$
}

\author{
Miguel Ángel Maldonado García²
}

\begin{abstract}
"Ejercitadlos por tanto a sufrir golpes que tendrán que aguantar un día; endureced sus cuerpos a la inclemencia de las estaciones, de los climas y los elementos, al hambre, a la sed, a la fatiga; bañadlos en las aguas estigias" (Rousseau, 1776, 2002: 13).
\end{abstract}

\section{Introducción}

Desde que William Shakespeare publicó La tempestad (1612) han aparecido, en estos cinco siglos diversas versiones de náufragos que colman las expectativas de una sociedad urgida de héroes y modelos paradigmáticos; estos ingresaron a la sociedad moderna y a la escuela que escenarios reclaman nuevas ediciones de Robinson Crusoe.

La metáfora del náufrago recobra vida en Emilio (1762) quien descubre al niño como objeto de análisis; posteriormente, se reconfigura en Simón Rodríguez quien lo conduce a Latinoamérica. En el punto de encuentro entre el siglo XIX y el XX, Rodó le da una nueva vida; lo propio hace José Vasconcelos $(1935 ; 1952)$ con su “De Robinson a Odiseo. Pedagogía Estructurativa” y más tarde Fernández Retamar con Calibán (1991) en las postrimerías del siglo XX. En intervalos de casi un siglo entre una y otra metáfora, el náufrago se reconfigura con nuevos bríos y significados, no solo en la literatura, también en el cine.

De igual manera, en los tres siglos posteriores a la producción de Emilio o De la educación $(1762 ; 2000)$ la psicología, la pedagogía y otras disciplinas, especialmente después de la segunda mitad del siglo XX, han persistido en estudiar al niño desde múltiples aristas, lo mismo que al adolescente y al adulto, habiendo producido una

\footnotetext{
1 Texto recibido el 16 de octubre del 2010, evaluado el 10 de noviembre del 2010 y arbitrado 20 de diciembre del 2010.

2 Doctorando en Educación, convenio interinstitucional Universidades Pedagógica Nacional, Valle y Distrital. Magister en Educación de la Universidad Pontificia Javeriana. Autor de Pedagogías críticas. Europa, América Latina y Norteamérica (2008), entre otras. El presente artículo es un producto investigativo de la tesis doctoral en proceso, titulada "Las ofensivas conceptuales sobre competencias en el campo de la educación superior. Período 1957-2004": avancemosenpedagogía@gmail.com
} 
inagotable cantera de enunciados con las que se constituyeron algunas prácticas pedagógicas de la escuela actual: al finalizar el siglo XVIII, Rousseau convirtió al niño en objeto de estudio y desde entonces diversas disciplinas perfeccionan sus métodos de indagación y se solazan en su labor.

Pues bien, nosotros tampoco escapamos de husmear al maestro y a su discípulo. Nuestra hipótesis es que Rousseau inauguró con Emilio la versión moderna del párvulo aprendiz y de su maestro. El maestro Rousseau se inventó un niño a su imagen y semejanza y quiso que fuera como el náufrago Robinson Crusoe; además, perfiló un modelo docente que cautivó a la sociedad y se instaló en la escuela. Desde entonces, los enunciados se recrean y se dispersan en prácticas discursivas como la literatura o la pedagogía y, de modo más reciente, en el cine. Simón Rodríguez, ferviente seguidor de Rousseau, creó un modelo de maestro y discípulo roussoniano en el propio Simón Bolívar y, quiso entrar a la escuela de Colombia; sin embargo, Joseph Lancaster le ganó la puerta e impidió su ingreso.

Simón Rodríguez es el discípulo latinoamericano más destacado de Rousseau, así como Simón Bolívar lo será de su maestro Simón Rodríguez; el punto de encuentro entre estos dos pedagogos ilustres lo situamos en una obra que es tanto literaria como didáctica: Emilio. Solo hasta comienzos del siglo XX se pensó en una versión fundada desde los postulados de Simón Rodríguez ${ }^{3}$ y medio siglo después, se pensó en la formación para el trabajo, como quería Rodríguez. Este argumento nos permite situar a Rodríguez como un pedagogo de la modernidad.

\section{Tesis parcial}

Cuando William Shakespeare escribió La tempestad ${ }^{4}$ (1611) para crear la metáfora o discurso de Calibán le dio la clave a Daniel Defoe para crear al náufrago Robinson Crosoe (1719). Rousseau, a su vez, tomó la clave de estos dos personajes para crear a Emilio (1762) como una metáfora del discípulo que sobrevive y aprende en medio de las adversidades; así como Simón Rodríguez contribuyó a crear un discípulo heroico y robinesco en su metáfora del libertador. En síntesis, William Shakespeare, Daniel Defoe, Juan Jacobo Rousseau y Simón Rodríguez, son cuatro maestros templados en el fragor de la vida que formaron, a su imagen y semejanza, héroes

\footnotetext{
${ }^{3}$ Destacamos que esta idea ya había sido trabajada en Mocedades de Bolívar del venezolano Rufino Blanco Bombona (1945) quien recalca la enorme influencia de Rousseau sobre Bolívar, fruto de las enseñanzas de su maestro Simón Rodríguez, pp. 86-87, algunos de los planeamientos de Blanco los recuperaremos en este breve texto, pero nuestro interés está puesto sobre Robinson Crusoe.

También hay en este texto una semblanza del profesor Philipe Meirieu quien escribió "Frankestein educador" (1998) y produjo una sugestiva ruta para seguir la pista a la educación e hizo de Frankenstein el educador de la modernidad. Meirieu se refiere a la novela publicada en 1818 como Frankenstein o el moderno Prometeo de la escritora inglesa Mary Shelly.

${ }^{4}$ La tempestad (1610) es el drama de comienzos del siglo XVII, fruto de la madurez literaria de William Shakespeare que cumplió 400 años de haber sido escrita pero que sigue incólume y vital.
} 
románticos shakesperianos en sus respectivos discípulos. En su orden, Calibán, Robinson Crusoe, Emilio y Simón Bolivar se tallan a sí mismos, encarnan náufragos heroicos y románticos que logran vivir y aprender en medio de un ambiente hostil para convertirse en los héroes de la modernidad, como querían sus maestros. Cada uno debe superar tensiones y obstáculos hasta convertirse en héroes.

\section{2, la avanzada del náufrago}

Casi 110 años después de La tempestad (1610), motivada por un evento real, será publicada la novela Robinson Crusoe (1719) para revivir la metáfora del náufrago. Pasados más de cincuenta años el náufrago viaja de Inglaterra a Francia y encarna en Emilio (1762) de Rousseau quien logra que su discípulo se convierta en el Robinson Crusoe del siglo XVIII. Luego, en el siglo XIX, desembarca en América de la mano de don Simón Rodríguez quien forja un discípulo romántico y heroico a su imagen y semejanza.

Así como La tempestad es uno de los más representativos dramas ingleses, Robinson es considerada la primera novela de la modernidad inglesa, nuestro héroe es un punto de quiebre entre el drama y la novela. El inglés Robinson Crusoe logra someter la naturaleza y a sus pobladores para su provecho, vemos en ello el tránsito de la producción artesanal hacia la industrial para ponerse en las puertas de la modernidad, mismo paso que se produce entre el drama y la novela. Robinson es un prototipo de la sociedad inglesa, tal como lo es Emilio para franceses y suizos.

Rousseau considera que Emilio es a su vez un soldado espartano, un solitario Robinson, un explorador y un héroe que se adapta y convive con la naturaleza; discrepa del concepto de explotar la naturaleza y propone convivir con ella. Si se enferma se cura a sí mismo, no puede ser un sujeto débil o incapaz de resolver sus propias necesidades: los males físicos o se destruyen o lo destruyen, la naturaleza puede ser su aliada o su enemiga, pero si logra someterla habrá logrado su objetivo. Confía solamente, como fuente de formación del niño, en dos libros, La República de Platón y Robinson Crusoe de Daniel Defoe; el primero lo considera útil para formar a su aprendiz en lo público, el segundo para formarlo como un ser singular. $\mathrm{Al}$ igual que los espartanos desecha la posibilidad de educar a un niño enfermizo o achacoso, Emilio es un náufrago solitario que no necesita filósofos ni sacerdotes. Denigrará de la ciencia y de su ímpetu contra la apacibilidad del hombre. A causa de su héroe, Rousseau será premiado y enaltecido a la vez que perseguido y vituperado; será un romántico europeo de su siglo.

Rousseau muestra así las contradicciones propias de la modernidad; en tanto que duda sobre el papel de la ciencia en la construcción del ciudadano, sabe de su importancia en la formación del sujeto, así como los riesgos que ella suscita. De otra

\footnotetext{
${ }^{5}$ Este será un texto guía para Simón Rodríguez, se lo entrega a Simón Bolívar quien lo llevará consigo a lo largo de su vida.
} 
parte, en la formación del ciudadano, con la recordación de La República, nos lleva a pensar que Emilio está más cerca de Esparta que de Atenas. Revisemos un par de líneas: "Tenía una espartana cinco bijos en el ejército, y aguardaba noticias de la batalla. Llega un ilota, y se las pregunta asustada: "Tus cinco bijos han muerto. - Vil esclavo, ¿te pregunto yo eso? - Hemos alcanzado la victoria». (2002: 4). Concluye luego: Cuando Emilio aprenda su oficio, quiero yo aprenderlo con él, porque estoy convencido de que nunca aprenderá bien lo que no aprendamos juntos. La misma pretensión mostrará Simón Rodríguez en la formación de su discípulo y en su autoformación o cuidado de sí, forjadas en los golpes de la vida y la experiencia.

Emilio es la metáfora del discípulo de Juan Jacobo Rousseau quien concibió su vida por sí mismo a la luz del náufrago Robinson Crusoe, héroe que tomará diversos rostros, se diseminará por Europa y América no solo en la pedagogía, sino en la literatura y el cine para crear nuevas subjetividades.

Rousseau abre en el siglo XVIII una discusión sobre la modernidad del maestro, preocupación que comprometió a los escritores románticos y a la ilustración, y crea un sujeto a su imagen y semejanza que será un paradigma en la gestación de los héroes del romanticismo, entre quienes se cuentan los dos simones en referencia: Simón Rodríguez, el maestro, y Simón Bolívar, el discípulo. El discípulo habrá de convertirse en nuestro mayor héroe nacional y en la metáfora del discípulo heroico, entre tanto su maestro pasará a la opacidad y será parte de una memoria esquiva a su nombre.

Para deconstruir la metáfora del aprendiz robinesco, viajemos a la Europa de Rousseau (Ginebra, 1712- Ermenonville, 1778) cuando este continente se debate en pugnas entre una monarquía decadente y una burguesía pujante, contempla cómo la formación de los artesanos se extingue ante las escuelas y universidades racionalistas y es testigo de las pujas religiosas entre parisinos católicos y ginebrinos luteranos con lo cual abren la discusión sobre el concepto de ciudadanía. En estas circunstancias se produce el nacimiento de Juan Jacobo, quien asume un sino trágico -mi nacimiento fue el primero de mis infortunios, declara en las primeras páginas de las Confesiones- es la causa de la muerte de su madre, razón que, - al parecer - hace de su padre un ser distante y un tanto apático, quien a causa de una riña debe abandonar Ginebra para dejar a su hijo expósito y enfermizo en manos de su tío. A sus dieciséis años, Juan Jacobo huye de su ciudad natal para emprender una vida ${ }^{6}$ errante, dura, solitaria y sibarita; se convierte en un buscón o un lazarillo, se aloja en los brazos de una dama que es al mismo tiempo su madre y amante, se convierte en católico entre los católicos siendo luterano, pero luego será, a su regreso a Ginebra, converso luterano, habiendo sido católico. Funcionario público ayer, mañana preceptor de niños. Músico, escritor, ensayista y aprendiz de químico, investigador, además de haber sido padre de cinco hijos a quienes dejó en el desamparo.

\footnotetext{
${ }^{6}$ Simón Rodríguez emulará su andadura y su interés por la ciencia. Anduvo por el Caribe, Estados Unidos, Europa y, a su regreso, recorrió desde Cartagena hasta Chile, sin quedarse quieto ni apático en ningún lugar.
} 
Europa siente el influjo del racionalismo renacentista que a su vez es cuestionado por la burguesía emergente la cual infla sus velas de pragmatismo productivo y la emprende contra la monarquía representada en el clero, la nobleza y su simbología medieval. Por su parte, el soporte del pensamiento ilustrado es el racionalismo, la secularización, el renacer del sujeto y la ponderación de la bondad natural del hombre. Así las cosas, el romanticismo que entusiasma a Rousseau se muestran primitivo y en abierta rebelión tanto contra la burguesía emergente como también contra el racionalismo ilustrado, pues considera que ambos están lejos del sentimiento popular que tanto eco hará en latinoamérica del siglo XX.

\section{Emergencia del niño en la modernidad}

Rousseau propone la metáfora de un niño llamado Emilio que nace como un salvaje y que habrá de convertirse en hombre en tanto se adapte y doblegue la fuerza de la naturaleza; a la sazón, perfila a un maestro quien estará siempre al lado del niño, del adolescente, del joven y del adulto; lo acompañará desde su nacimiento hasta que contraiga matrimonio y se convierta en ciudadano. Sin ser un maestro dominante, sí es una suerte de espejo, un asomo de compañía que no enseña a su discípulo y que lo deja a la intemperie y solo interviene cuando este es incapaz de superar un obstáculo o de alcanzar una meta. La relación entre maestro y alumno es recíproca y natural, tanto como la relación entre madre e hijo: sin madre no hay hijo, sin discípulo no hay maestro, afirma Rousseau.

Sin bien es cierto, Rousseau no es el único descubridor de la infancia sí es quien inaugura un método para contrastar las profundas diferencias físicas y espirituales entre niños y hombres. Observa las manifestaciones de los sentidos con los cuales el niño va construyendo su propio mundo y abriéndose camino en la maraña de la vida. Las paradojas alrededor de su relato son diversas, aunque plantea que el maestro es solo un guía que está pendiente de los cambios espontáneos cualitativos y cuantitativos de los niños, propone sin contemplaciones una especie de formación espartana: "Ejercitadlos por tanto a sufrir golpes que tendrán que aguantar un día; endureced sus cuerpos a la inclemencia de las estaciones, de los climas y los elementos, al hambre, a la sed, a la fatiga; bañadlos en las aguas estigias" (Ibíd, 2002: 13).

Podría decirse que Rousseau observó en el niño a un ser tosco y torpe que necesita ser corregido para convertirlo en un buen sujeto social. Tanto Emilio como El contrato social construyen la versión de ciudadano de la modernidad, en ambos textos le apuesta a una educación mediada por la naturaleza, los hombres y las cosas: Rousseau comprende que un sujeto en crecimiento es una imagen de la naturaleza que cambia sin que nadie intervenga directamente. Considera que el niño aprende con la experiencia y la ayuda de un maestro o un vigía distante y silencioso; pero advierte que el aprendizaje debe ser práctico "conveniente para el hombre y que se adapte al corazón humano". Para Rousseau, los saltos entre el recién nacido y el niño, entre el niño y el infante, entre el infante y el adolescente, y entre este y el hombre están 
regulados por la naturaleza. En tanto que el maestro comprenda la importancia de la fuerza de la naturaleza humana, con todo y adversidades, estará en condiciones de dirigirla hacia buen puerto para hacer del niño un hombre o un ciudadano, antes que un magistrado, un militar o un sacerdote. Pero ante todo "El oficio que quiero enseñarles es el vivir", dice Rousseau o mejor, el maestro de Emilio.

En las Confesiones describe los maestros que templaron su carácter cuya esencia reaparece en el perfil del maestro de Emilio, quien, al igual que Juan Jacobo, queda desamparado y a disposición de su maestro. "Nada importa que vivan sus padres y su madre, encargado yo de todas sus obligaciones, adquiero sus derechos todos. Debe honrar a sus padres, pero solo a mi debe obedecer; esta es mi primera, o más bien mi única condición”. Rousseau anhela el regreso a la educación de los artesanos feudales quienes dejaban a sus hijos siendo niños en manos de un maestro para devolverlos a sus padres después de los veinte años, convertidos ya en trabajadores o maestros de oficios.

Muchas escenas de Emilio se repiten en las Confesiones (1782) en las cuales Rousseau desnuda su alma sin reserva y muestra su vida hecha en medio de la pobreza y la incredulidad social, desde su infancia hasta su senectud, tanto en su papel de aprendiz de la vida como de maestro; se muestra no menos errabundo y guerrero que Robinson: lo mismo harán Simón Rodríguez y Simón Bolívar, cuatro seres huérfanos y casi expósitos.

\section{Artesanos y académicos}

La Edad Media, y aun el Renacimiento, exaltó al maestro, artista o artesano que luego, con el advenimiento de la sociedad industrial, será convertido en profesor o docente: comerciantes, fontaneros, cerrajeros, pasteleros, zapateros, hilanderos forjaron los oficios y marcaron el horizonte para los aprendizajes relacionados con el trabajo de los gremios artesanales que eran orientados por los maestros. Mientras en las universidades los académicos formaban en artes nobles o liberales - teología, gramática, matemáticas o ciencias jurídicas, que no estaban asociadas al concepto de trabajo sino al de disciplina-, los gremios artesanales formaban a los trabajadores -en agricultura, carpintería-: los académicos eran expertos en una disciplina y los artesanos en un oficio. Los profesores se instalaron en las universidades, en tanto que los maestros lo hicieron en los talleres y luego en las fábricas; la separación entre oficios y disciplinas o profesiones se acentuó. De una parte, hay maestros que forman para los trabajos productivos, para el manejo de las artes manuales, de otra, hay disciplinas ligadas a la lectura, la escritura y a la producción científica, y también a la especulación.

El proceso de formación, en el escenario de los oficios, pasaba por tres etapas: aprendiz, oficial y maestro. Los artesanos no trabajaban para un patrón en particular y vendían sus productos sin rendir muchas cuentas, además de ser personas respetables y reconocidas. 
Por su parte, los sistemas escolásticos residentes en las universidades creadas dos siglos atrás de Rousseau profesaban culto al trivium y al cuatrivium y miraban con desdén el trabajo de los artesanos. Nuevas interpretaciones sobre lo natural y lo humano le quitarán el encanto y el espíritu místico a las universidades: el empirismo y el positivismo darán cuenta de una realidad hasta ahora ajena. El siglo de las luces está en su apogeo y Rousseau, anárquico, parece tomar la ruta al pasado: el cristianismo, desestimación del arte, el regreso a la naturaleza, lo sensitivo primero que la racional. Con tantos hallazgos unos y otros sienten la presión, los maestros artesanos no alcanzan a responder a la ciencia y a la producción y al igual que los escolásticos, ceden espacio a otros saberes más útiles. Mientras para los cortesanos Rousseau es un insurrecto para algunos enciclopedistas es un reaccionario conservador.

Rousseau es testigo de la crisis religiosa, de cambios científicos, así como de las dificultades y desigualdades entre una clase monárquica incapaz de trabajar y producir bienes frente a una burguesía en ascenso que genera rápida y progresivamente riqueza a costa de los antiguos maestros y artesanos; manifiesta entonces de modo categórico:

No es justo que lo que un hombre ha hecho por la sociedad, exima a otro de lo que debe hacer; porque como cada uno se debe entero, ninguno otro puede pagar más que por sí; ningún padre puede dejar por herencia a su hijo el derecho de ser inútil a sus semejantes (...) Así, el trabajar es obligación indispensable del hombre social. Rico o pobre, fuerte o débil, todo ciudadano ocioso es un bribón (Las confesiones, 2002: 252).

Rousseau denigra de las aulas, los pizarrones, cuadernos o pupitres, su proyecto está más en lo corporativo y productivo, está más cerca de la tecnología que de la cátedra magistral. El ginebrino percibió un problema social en la relación entre educación y ciencia propio de la modernidad y se pone del lado del proceso formativo, corporativo y gremial, eminentemente práctico: el niño entraba en un plan de aprendiz, luego acreditaba su aprendizaje ante los gremios artesanales para convertirse a los veinte años en oficial hasta llegar, después de haber trabajado al pie de su tutor; la meta era llegar a maestro, con el reconocimiento de los gremios y de la sociedad. A lo largo de esta formación se mantendrán dos componentes: uno pedagógico y el otro social, empapados ambos de tres máximas fundamentales: el amor y temor a Dios, la fidelidad y la obediencia ciega al maestro que para serlo debió pasar por un proceso largo y de gran tenacidad: "Más quiero que sea zapatero que poeta; más quiero que empiedre los caminos reales, que no que haga flores de porcelana" (1762; 2002: 182).

Rousseau se ve medio de las dos opciones formativas y se enfrenta a una disyuntiva. En ambos casos se mantendrán dos componentes: uno didáctico y el otro social, empapados ambos de dos máximas fundamentales: primera, el amor y temor a Dios y segunda, la fidelidad y la obediencia ciega al maestro. El ingreso a una u otra solo se daba para quienes tenían la capacidad de pago: mientras que los nobles iban a la universidad, los artesanos iban al taller del maestro. 
Europa, en una eclosión extensiva, ya no será la misma; desde entonces, la razón y el interés por lo fáctico y objetivo mostrarán otras mentalidades e imaginarios: ahora todo puede ser objeto de la predicción matemática y del cálculo, pero también todo aprendizaje puede ser objeto de producción.

Concluye así: Cuando Emilio aprenda su oficio, quiero yo aprenderlo con él, porque estoy convencido de que nunca aprenderá bien lo que no aprendamos juntos. Simón Rodríguez, el maestro de Bolívar, se habrá de expresar de la misma forma cuando sugiera que las nacientes naciones latinoamericanas deben educar a sus ciudadanos para el trabajo y no en latín o gramática provenientes de Europa.

Rousseau propone dos fines educativos: primero, estimular la capacidad de vivir en soledad y, segundo, lograr autosuficiencia a más de establecer equilibrio entre la voluntad y el poder o libertad y autoridad. Para él, la naturaleza humana otorga las facultades necesarias para la conservación y defensa. Destaca con un sentido práctico la antelación de la acción sobre la inferencia, Emilio nunca sacará conclusiones sobre los razonamientos, sino desde las evidencias o desde los hechos; al decir popular, obras son buenas razones o los conoceréis por sus hechos, precepto clásico de la productividad y reafirmación del Robinson con quien venimos cabalgando en este texto.

\section{De Rousseau a Simón Rodríguez}

Propusimos que Rousseau reencarna en Simón Rodríguez y en Simón Bolívar. Robinson Crusoe es el punto de encuentro y la metáfora del maestro o docente en interdependencia con su discípulo. A partir de ahora buscaremos puntos de contacto entre Rosseau y Simón Rodríguez, extractemos unas líneas de modo literal del pensamiento de Rodríguez quien se refiere al oficio docente de la siguiente manera: EL MAGISTERIO ES UNA PROFESIÓN El que reemplaza a los Padres de familia, ejerce las funciones de puede común, por consiguiente debe ser elejido por sus aptitudes que son ser dueño de la materia que promete enseñar, conocer el ARTE de enseñar. Rousseau, ya lo anotamos, prefiere verse más como maestro que como catedrático, Rodríguez actualiza este discurso, veamos: Hágase la diferencia, entre profesor, catedrático, i maestro. Catedrático es el que enseña SENTADO EN ALTO: porque cátedra significa PUESTO SUPERIOR O EMINENTE: i no se usa dar este título, sino al que enseña Teolojia, Filosofía, Derecho, o Humanidades. Pero puede úno ser Profesor o Catedrático, i no ser Maestro. (Rumazo, 2001: 17 a 19, conservamos la puntuación, mayúsculas y gramática del texto original).

Rousseau emerge en Simón Rodríguez, maestro del Libertador y su discípulo encarna la idea del niño que aprende y del maestro que forma, creando así una metáfora ideal. Bolívar, el discípulo, es un soldado raso que logra superar todos los obstáculos hasta hacerse hombre y convertirse en héroe; su maestro Rodríguez, es un ser que observa en la distancia, en procura de evitar caídas o desviaciones, pero sin intervenir de facto. 
La reciprocidad entre el que enseña y aprende debe ser de interdependencia y es un rasgo que caracteriza al maestro y su discípulo, misma que se da entre padre e hijo con lo cual se traza una diferencia entre el concepto de docente y el de maestro, como quería Rousseau.

\section{Simón creador de escuelas y métodos pedagógicos}

¿Pero, quién era Simón Rodríguez? En nuestra búsqueda, descubrimos a un hombre que, físicamente, nunca fue niño, al menos así lo quieren sus biógrafos quienes rara vez hablan de su niñez, aunque siempre lo muestran vital e irreverente, curtido en los aprendizajes que le dejaran Estados Unidos, la Vieja Europa y el trópico, el viento ribereño del Orinoco, las gélidas montañas andinas, la brisa marina del Caribe y del Pacífico; diseñado por la experiencia de la vida y las irreverencias contra una sociedad monárquica, colonial e incapaz de comprender su pensamiento de vanguardia. No solo aprendió la lengua de Shakespeare, Rousseau o Comenio, además exploró el quechua. Macizo su rostro, de estatura media y atlética, cubierto con anteojos de aros metálicos, de traje descomplicado, medio desnudo, mas bien bajo; mestizo él, latinoamericano en esencia: nos referimos a don Simón Narciso Rodríguez, autodenominado Samuel Robinson ${ }^{7}$, el maestro del Libertador.

No es fácil seguirle la pista y capturarlo pues su vida se diluye en mil rincones y viajes; además, en la posteridad de los años, el olvido y menosprecio del que fue objeto por parte de sus detractores opacaron su obra.

Nuestro Robinson fue maestro aquí y allá errante inquebrantable en su larga vida de más de setenta años; siempre fundando escuelas, primero en Caracas sitio en donde respondió a la lista de estudiantes el joven Simón Bolívar y posteriormente en las nacientes ciudades latinoamericanas como Bogotá, Chuquisaca, Arequipa, Valparaíso y también en Europa. Sus escuelas que, por entonces, eran las mismas casas en las cuales vivían, amaban y sufrían los maestros. Otra suerte de escuelas se dio en las barberías y peluquerías de Caracas, de las cuales hará burla nuestro maestro. Su labor de maestro, de acuerdo con Rumazo, la ejercerá en siete países de Europa y cinco de Suramérica (Rumazo: 22).

Desde la casa de los Bolívar, que pronto abandonará, se trazan las primeras líneas del proyecto bolivariano. En 1791, el Cabildo de Caracas le otorga el título de maestro que inicia en su casa: un año después ingresa a la casa de la acaudalada familia Bolívar para encontrarse con el libertador aún niño. Nuestros dos héroes se encuentran en su mocedad; el niño había quedado sin padre a la edad de tres años (1790) para quedar en la orfandad total tras la muerte de su madre. Ese año, el abuelo del niño se lo dará en custodia a un joven díscolo pero estudioso. Señala

\footnotetext{
${ }^{7}$ Señala Rumazo que al salir de Caracas, ciudad a la que nunca regresará, cambia su nombre de pila por el de Samuel Robinson por un lapso de 26 años hasta su regreso a Cartagena (Op. cit., p. 47). Esta señal motivó el trabajo arqueológico fruto de este artículo de investigación.
} 
Rufino Blanco que: Profesores había tenido hasta entonces; maestros no. El maestro por antonomasia es don Simón Rodríguez (...) Antes de don Simón había tenido al capuchino Andujar, de primeras letras, de religión, de moral, de gramática española; Andrés Bello, solo dos años mayor que Bolivar, de aritmética, geografía y cosmografía; Guillermo Pelgrón, de latín. También tuvo otro profesor de nombre Vides. Ninguno dejó huella en él (Blanco, 1945: 86).

En el marco de una sociedad colonial y temerosa del influjo francés, Rodríguez y Bolívar son dos seres expósitos y al acecho reunidos al desgaire, pareciera que los mayores quisieran quitarse la marcación del acaudalado pero huérfano niño para dejarlo en manos de un ser solitario. Mientras que el joven maestro se apea en el niño para recrear sus aprendizajes libertarios y románticos, el niño busca refugio y lo encuentra. Son de esos eventos caprichosos de la historia en los que las fuerzas se atraen para ventura o desventura de la memoria. Esta condición nos permite pensar en la relación filial y de interdependencia señalada con la cual se crea el concepto de maestro y de discípulo y que diferencia al catedrático, según Simón Rodríguez.

\section{La literatura del maestro Simón Rodríguez}

A la sazón de director de la escuela de Caracas, Rodríguez tuvo acceso a la literatura contemporánea que circulaba en España por el respaldo recibido al comienzo de su labor educativa gracias a que los pedidos de los libros debían hacerse solo por las autoridades. Además, gracias al contrabando y a pesar del acicate de la Inquisición, nuestro Robinson fue lector de los pedagogos franceses y de los sociólogos ingleses que llegaban a estas tierras en los barcos de los piratas que además traían botellas de whisky, brandy, telas y los anhelados libros de la intelectualidad criolla, también prohibidos en la convulsa España.

En su natal Caracas inició su labor crítica, generó controversia y hubo de retirarse por la presión del espíritu colonialista imperante. Fue director de la Escuela Primaria y desde allí tropezó con las costumbres y las ataduras criollas: llegar, por entonces a este cargo era una labor complicada. No era fácil formar a los hijos de los comerciantes españoles millonarios y de los criollos dueños de enormes haciendas; estos padres de familia se cuidaban de que los profesores fueran gente de bien, respetuosa de las costumbres, conocidos por su honestidad y buenas maneras.

La situación de las colonias se hacía tensa, don Simón huye de Caracas ${ }^{8}$ a la isla de Kingston en 1797 ante el riesgo de ser acusado de conspirador, de allí pasará a Estados Unidos en el fervor libertario de George Washington, permanecerá por tres años para desde allí embarcarse a Europa. Alemania, Italia, Rusia, España, Polonia y Francia lo retuvieron por casi veinte años. Rodríguez parece obedecer la sugerencia

\footnotetext{
${ }^{8}$ A partir de entonces toma el seudónimo de Samuel Robinson. Antonio Ocampo, Uslar Prieti y Rumazo coinciden en señalar que Rodríguez emuló, no solo con el seudónimo, el sentido profundo inmerso en Robinson Crusoe desde cuando emprende su largo viaje hacia en un peregrinaje al que solo puso punto final con su muerte.
} 
de Rousseau en cuanto a los viajes y conocimiento del afuera; regresa luego a Latinoamérica para seguir en su errabunda e infructuosa labor.

Simón Rodríguez entre sus largos viajes por Europa, participó en esos movimientos, observó, registró, reflexionó y actuó: intelectual errante, revolucionario insobornable, pedagogo, formador de formadores y fundador de escuelas. Los dos Simones se encontrarán años después en Europa, entre la bohemia, los placeres y una que otra angustia. En 1804, el discípulo estaba desecho ante la muerte de su esposa por lo cual se refugió en Paris en donde devora a Bacon, Voltaire, Locke, Cervantes y por supuesto a Rousseau, pero además vuelve a ser discípulo de Rodríguez, sin que ahora exista el control o sojuzgamiento de Caracas; se pasean por las cortes, salones, museos, calles y suburbios de Paris, Milán, Londres o Roma. Este es el año del mítico juramento del Monte Sacro en Roma que habrá de cumplir con creces en una América colonial acostumbrada a la cotidianidad de la servidumbre y al azote español sobre la espalda: Bolívar dará mejor ejemplo de su formación espartana y heroica que propuso Rousseau y materializó su maestro Simón Rodríguez.

Andanzas van, guerras vienen, pasarán más de veinte años para su cita en Quito en donde el viejo le propuso lo siguiente a su discípulo, ahora general y presidente de la Gran República de Colombia: "Creense escuelas en donde se enseñen los oficios de carpintería, albañilería; suprimase tanto latín, de que le sirve a un indígena saber del griego; enséñesele el quechua. La escuela debe ser mixta, darle ocasión a las niñas que demuestren que valen lo mismo que los niños. El trabajo debe mezclarse con los juegos” (Blanco, 1945: 70).

\section{Simón Rodríguez en la modernidad latinoamericana}

Sostenemos que así como Rousseau se introdujo en la modernidad europea, lo propio harán Simón Rodríguez y su discípulo quienes se formaron para la libertad: anduvieron, leyeron, observaron, actuaron y se expusieron; es decir, se atrevieron a salir de su propio tiempo; o lo que es igual, pensaron y actuaron para la modernidad. Rousseau interviene de manera especial la idea del sujeto educativo y Rodríguez en la idea de hacer de la educación una práctica popular y al servicio de la producción.

En 1825, Bolívar recomendaba la creación de una Escuela de Ingeniería Civil; señalaba la abundancia de médicos y abogados mientras faltaban muchos mecánicos y agricultores, verdaderos creadores de la riqueza y el bienestar (Bohorquez, 1956). Tales iniciativas del libertador, habían sido estimuladas por su maestro Simón Rodríguez; sin embargo, la población en general no se formó y el estado de analfabetismo, atraso, sumisión y ausencia de procesos productivos en las incipientes ciudades y en el campo fue absoluto por más de un siglo.

Lo único que le pedí (refiriéndose a Bolívar) fue que se me entregaran, de los cholos más pobres, los más despreciados, para irme con ellos a los desiertos del Alto Perú - con el loco intento de probar que los hombres pueden vivir como Dios les 
manda que vivan- porque Dios antes de hacerlo sabía (...) el redentor pedía Párvulos para enseñarlos; porque quiso hacer ver al mundo que de judíos viejos, poco o nada se podía esperar y para probarlo les pidió que lo martirizaran. ${ }^{9}$

\section{9, edición de los preceptos de educación de Simón Rodríguez}

En varios textos de Colombia y Venezuela de mediados del siglo XIX se muestra la preocupación por recuperar la producción de Simón Rodríguez la cual se sintetizó bajo el título "Extracto sucinto de mi obra sobre la producción republicana" que fue publicado en 1849. Este texto grafica su punto de vista sobre la "Educación para los pobres de Hispanoamérica" "10 la educación pública, las obligaciones del estado, la responsabilidad de los maestros, la relación entre educación, trabajo y empresa, el concepto de República y Educación. Si se observan los postulados y la tardanza en la edición de sus textos se evidencia que Simón Rodríguez fracasó en su momento en su proyecto educativo, si bien hubo un entusiasmo febril frente al triunfo sobre los españoles, muchas tareas estaban por iniciar, entre ellas la educativa; intentó instalar sus escuelas y talleres, a veces con presupuesto, en varios lugares de Suramérica pero no logró convencer a los lugareños que lo encontraban estrambótico y díscolo. Bolívar y Santander, en su afán de neutralizar el poder español en las tierras liberadas y otear en el horizonte inglés apelan al modelo lancasteriano o sistema de enseñanza mutua, $\sin$ duda, más eficiente y barato.

De acuerdo con Saldarriaga las condiciones de posibilidad de una escuela distinta a la propuesta por Lancaster era remota. Ante el reducido número de maestros y una masa iletrada de jóvenes y niños, la propuesta de Joseph Lancaster encajaba perfectamente: "la letra con sangre entra, y la labor con dolor", se acompañó de otra frase lapidaria: "un lugar para cada cosa, y cada cosa en su lugar". Señala Saldarriaga que el castigo o el premio era físico y moral: el palmetazo, el cepo o el confinamiento; carteles colgados al cuello o gorros con el sello de "perezoso", "distraído", "burro", "puerco" eran el estímulo para quienes se distraían, se equivocaban o no cumplían con las normas. Por el contrario, a quienes hacían bien la tarea y cumplían con las normas, se les estimulaba ascendiéndolos de puesto en la fila o convirtiéndolos en monitores; además, ganaban el derecho a propiciar el castigo a sus condiscípulos (Saldarriaga, et. al, 1997: 189).

Este método empleado en la formación de las clases más pobres alcanzó a desplegarse en muchas escuelas latinoamericanas y a generar un imaginario en la educación que se coló en la médula social y que aún muestra sus secuelas. El maestro Rodríguez

\footnotetext{
9 Extracto de la obra "Educación republicana" 1849. Tomo I. Obras escogidas de Simón Rodríguez, Caracas 1985.

10 Ver: "Extracto sucinto de mi obra sobre la educación republicana". Presentación del documento, Javier Ocampo López, En: Revista de historia de la educación latinoamericana, Rudecolombia. No. 9, Universidad Pedagógica y Tecnológica de Colombia, 2007.
} 
fue testigo ocular de estas prácticas sobre las que guardará celo en atacarlas o emprender un ataque directo, por consideración con su discípulo. No obstante que cada una de sus intervenciones son una negación del infame método inglés. De acuerdo con Rumazo, Robinson, octogenario ya, hizo la siguiente referencia implacable: " $\mathrm{La}$ enseñanza mutua es un disparate. Lancaster la inventó para hacer aprender la Biblia de memoria. Los discípulos van a la escuela a aprender, no a enseñar, ni a ayudar a enseñar. Dar gritos y hacer ringorrangos no es aprender a leer ni a escribir. Mandar recitar lo que no entiende, es hacer papagayos para que por la vida sean charlatanes" (Ibíd. p. 76).

Las pretensiones de inclusión de prácticas de educación para el trabajo propuestas por Rodríguez cayeron en suelo estéril. La incipiente Colombia en la que vivió el maestro estaba lejos de experimentar un proceso de industrialización y quienes intentaron cambiar las prácticas colonialistas transitaron por caminos minados de escollos: el atraso económico, tecnológico de finales del siglo abrazó a la educación colombiana durante el siglo XVIII y todo el XIX, dejando secuelas imborrables.

Rodríguez mostró preocupación por vincular educación y trabajo desde el comienzo de la República cuando se planteaba la necesidad de diseñar modalidades educativas que contribuyeran con el desarrollo de las fuerzas productivas para su desempeño en la minería, la agricultura y la industria. Crear escuelas en donde compartieran niños y niñas para enseñar de carpintería, albañilería; suprimir el latín y el griego a cambio del quechua y en donde el trabajo y el juego se mezclen sin reserva son expresiones de la modernidad en Rodríguez.

A su regreso de Europa y luego del desembarco en Cartagena, en 1824 en Bogotá, funda la escuela o "Casa de Industria Pública", semilla de las escuelas taller propias del siglo XX y reflejo de sus lecturas de Emilio y de su interpretación de las escuelas artesanales que vio en Europa: "Las artes mecánicas están en esta ciudad y aun en la provincia como vinculadas a los pardos y morenos. Ellos no tienen quien los instruya; a la escuela de los niños blancos no pueden concurrir; la pobreza los hace aplicar desde sus tiernos años al trabajo, y en él adquieren práctica, pero no técnica; unos se hacen maestros de otros, y todos no han sido ni aun discípulos" (1988, Oliveri, 186).

¿No es este acaso el puño de Rousseau en la pluma de Rodríguez? No obstante, pasada la guerra, otros asuntos distraerán el foco de interés de la educación. La situación económica y administrativa era incipiente, a más del escaso interés por la educación. Atreverse a proponer la formación para el trabajo, cuestionar la enseñanza del latín o griego, plantear la enseñanza del quechua o reunir en una misma escuela a niños y niñas, sin duda era una empresa incomprensible además de arriesgada. Se comprende entonces el fracaso del proyecto del maestro Simón Rodríguez. 


\section{Variaciones del discurso}

De acuerdo con lo visto en los párrafos anteriores, hay una suerte de continuidades y discontinuidades histórico literarias y pedagógicas entre Robinson Crusoe desde la emergencia de Emilio que desde entonces sitúan al aventurero, náufrago y héroe como un ser paradigmático para la educación de la modernidad. Shakespeare y Daniel Defoe crean su náufrago, dejándolo a la buena de Dios en una isla solitaria en donde tiene que arreglárselas para sobrevivir al amparo de su genialidad, capacidad de adaptación a la naturaleza y despliegue físico. En su solitario y andariego personaje hay un poco del aventurero Alejandro Selkirk (sujeto de carne y hueso en quien se inspira Defoe), pero también mucho del propio Daniel Defoe y, años más tarde, del errabundo, perseguido y genial Rousseau, y entre estos dos, un poco del guerrero espartano y del apóstol judaico cristiano. Con el ser solitario, guerrero, apóstol, aventurero y náufrago se escribirán algunos enunciados de la pedagogía moderna sobre la cual han circulado múltiples lecturas, una de las cuales ingresa a Colombia de la mano del andariego y aventurero Simón Rodríguez o Samuel Robinson. Antes y después de Robinson Crusoe se producen discursos que se han reactualizado y dosificado en diversas formas para configurar prácticas discursivas y modelos educativos de la modernidad.

Algo semejante ocurre con las preocupaciones sobre el docente y el estudiante y sus implicaciones éticas y sociales que emergen y desaparecen cada cierto tiempo en otros escenarios y con trajes nuevos.

Las variaciones discursivas (Foucault, 2005) se producen según su poder ritual y según lo que son capaces de hacer y decir, han definido la voluntad de saber en distintos períodos de la historia. La tempestad, Robinson Crusoe y Emilio conducen a la metáfora de un maestro y un discípulo de la modernidad. Son observados como sujetos románticos y heroicos y como discípulos creados a imagen y semejanza de sus maestros: Calibán, Robinson Crusoe y Emilio encarnan en Simón Bolívar y en su maestro Rodríguez. La lectura de estos discursos pedagógicos ha generado una forma de mirar y una función que prescribe la falibilidad y veracidad de los discursos que han ido tomando forma en las instituciones educativas y en prácticas pedagógicas que se distribuyen en los libros, las bibliotecas, las sociedades de expertos, academias o grupos de investigación y laboratorios y también en el cine. La sociedad los reconoce, los distribuye y los legítima, generando dispositivos de poder y de prácticas. Vemos que algunas prácticas y formas de ver la pedagogía se instalaron desde el siglo XVIII y han venido tomando cuerpo en disciplinas como la psicología, la sociología u otras disciplinas para fundarse, racionalizarse y justificarse. Rousseau no solo descubrió los niños sino que los convirtió en objeto de análisis para dejarlos en la mesa de disección de la psicología, la medicina, la sociología y otras disciplinas de la modernidad. 
Rousseau actualiza a Robinson, lo mismo hace Simón Rodríguez con Rousseau. Luego Rodó (1900), José Vasconcelos (1935) y Fernández Retamar (1991) retoman a Calibán y Ariel, parientes de Robinson. Las preocupaciones rousseaunianas sobre la ciencia, el sujeto, el maestro ingresan a Latinoamérica, así como en la discusión sobre el ser latinoamericano; es decir, son actualizadas en una nuevas estéticas y en períodos distintos; desde entonces, hay nuevos mensajes con los mismos sujetos que visten otros trajes; así, Calibán, Robinson y Ariel, seres de la ficción y de la estética, se convierten en enunciados educativos y del saber que se despliegan en una ubicuidad que parece lineal pero que es demasiado porosa y fragmentada. Sus antagonismos absorben las disputas políticas y captan el interés de tirios y troyanos.

Algunos textos producidos desde La tempestad y después de Robinson de Daniel Defoe se dispersan y traslapan en diversos discursos. La literatura y el teatro fueron los medios esenciales para hacer la transposición discursiva entre los siglos XVII y XIX, pero en el siglo XX el cine y la televisión ganan el privilegio de llegar al público con mayor fuerza y rapidez. Recuperemos ahora algunas muestras cinematográficas para corroborar nuestra hipótesis.

Podríamos afirmar que el carácter solitario y taciturno del Calibán de La tempestad de Shakespeare emerge en Robinson Crusoe ${ }^{11}$ quien deviene en un espíritu práctico, trashumante y guerrero. A su vez, Jonathan Swift (1667-1745), contemporáneo de Defoe, con Los viajes de Gulliver, Julio Verne (1828-1905) con Los bijos del Capitán Grant; Robert Louis Stevenson (1850-1894) con La isla del tesoro (1883) se recrean entre sí. Algunos de los grandes escritores se dejan cautivar por la metáfora. Huelga decir que tampoco Gabriel García Márquez resistió la tentación de hacer su propio Relato de un náufrago (1958); de la misma manera Robinson cautivó al cine y a la televisión, todos son practicantes de la reiteración discursiva.

\section{Robinson entra al cine}

En el cine son diversos los robinsones ${ }^{12}$, destacamos la producción del célebre francés George Méliès (1902), Les aventures de Robinson Crusoe y del español Luis Buñuel, Las aventuras de Robinson Crusoe (1952). De modo más reciente, el actor Tom Hanks se vistió de "El náufrago" (2000), bajo la dirección Robert Zemeckis, en un escenario en el que Viernes, personaje de Robinson Crusoe, es reemplazado por "Wilson", un balón de voleibol que se convierte en su única compañía en la inhóspita isla. El rastreo nos muestra que desde que el cine se convirtió en un medio masivo, la temática del náufrago ha cautivado el interés de los productores, del público y de los empresarios.

\footnotetext{
11 Ver: Ernesto Del Gesso, Antes y después de Robinson Crusoe, (2007) Rosario, Argentina, enhttp:// librosenblog.com. Consulta realizada en febrero de 2010.

${ }^{12}$ En la pesquisa adelantada, identificamos diez películas desde Méliès, (1902). Les aventures de Robinson Crusoe hasta El náufrago de Zemeckis, R. (2000).
} 
Arranz hace una reflexión sobre "Shakespeare en el espacio del Planeta prohibido. Adaptación de La tempestad”. Arranz señala: "La literatura es cíclica en sus hallazgos. No porque los autores recurran al plagio (que también), sino porque las viejas inquietudes, susceptibles de plasmarse líricamente en una obra acabada, perfecta, laten en cada hombre nuevo (p.198). Recordemos que Calibán ${ }^{13}$ es el nombre de un personaje de la película Planeta probibido" (1965). Arranz se refiere al eterno retorno con lo que se acerca más a Nietzsche que a Foucault, es decir, encuentra una repetición lineal e inexorable.

\section{A modo de conclusión}

Es dable hacer una lectura de los héroes Calibán y Robinson Crusoe desde la perspectiva con la cual se ha construido la subjetividad del sujeto latinoamericano. Hacer la lectura con este prisma permite ver a Rousseau, Simón Rodríguez y Simón Bolívar y luego a Rodó y Fernández Retamar, así como a Luis Buñuel y George Melies como constructores de las metáforas de la modernidad del sujeto maestro y su discípulo y ofrece una comprensión del sujeto docente y su discípulo desde otros ángulos.

Desde cuando Rousseau descubrió a los maestros y sus discípulos como seres moldeables se han producido diversas indagaciones sobre estos sujetos. En países y contextos que presentan crisis políticas y educativas se han producido diversos discursos sobre la construcción de un nuevo sujeto, sobre la utopía de atrapar en un modelo al hombre. Después de Rousseau emergió un héroe solitario, superdotado, espartano y con un dejo romántico e ideal. La producción cultural y académica está inundada de textos sobre su desempeño, atributos, afanes y limitaciones.

En nuestro ejercicio escritural quisimos ver que la construcción del significado de maestro y discípulo se instaló en la gestación de una metáfora de un ser ideal, creado a imagen y semejanza de un maestro gestor de vida, ambos tienen una mitad humano y otra mitad divina, de las que siempre habrá algo por decir. La forma en que se cruzan y se reencuentran los discursos se produce en un marco de tensiones sociales que ven en la metáfora del héroe náufrago la utopía que algún día podrá ser alcanzada. Vemos más en cada momento y lugar una serie de sucesiones, de fuerzas que se contraponen entre disputas discursivas para generar la metáfora de un sujeto que renace al amparo de sucesos históricos que a veces guardan semejanzas sin que haya una lógica de secuencia y consecuencia.

Simón Rodríguez comprendió el sentido práctico, racional, analítico, sistemático y, en esencia didáctico de Rousseau; comprender esta perspectiva lo sitúa en la modernidad. Para nosotros, el presente de don Simón Rodríguez está en el pasado de Rousseau, así como el presente y futuro de Rodó y Fernández lo está en el pasado y en el presente de estos dos. Si bien es cierto no hay una línea continua entre los discursos de Shakespeare, Defoe, Rousseau, Simón Rodríguez, Rodó, Vasconcelos

\footnotetext{
${ }^{13}$ Calibán también es el nombre de una banda alemana de heavy metal.
} 
y Fernández ${ }^{14}$ sus textos literarios crean sujetos y generan una serie de enunciados que toman cuerpo entre siglo y siglo entre un lugar y otro y sin importar cuándo o dónde.

También en el cine y en la literatura hay una serie de enunciados básicos para entender el perfil del sujeto y desde allí comprender al maestro y su discípulo. Pero dejemos a Borges en su imagen de la eternidad que es sabia y precisa: Las antesalas se confunden con los espejos, la máscara está debajo del rostro, ya nadie sabe cuál es el hombre verdadero y cuáles sus ídolos. Y nada de eso importa; ese desorden es trivial y aceptable como las invenciones del entresueño (Borges, 1996: 412). El cine y la televisión recuperan la metáfora del héroe y náufrago que encarna en las escuelas de hoy, tema que dejaremos en suspenso por ahora.

Hoy se acentúa el interés de indagar al maestro, tanto como al niño, las investigaciones de la primera mitad del siglo pasado no eran abundantes, pero en los últimos cincuenta años con la expansión de la escuela ${ }^{15}$ el interés creció para dar pie a que los psicólogos, pedagogos, sociólogos, economistas pensarán al niño como un sujeto que puede ser instruido, como un sujeto que aprende, como un paciente con problemas físicos y espirituales o como un dato que puede ser contabilizado en las estadísticas educativas o económicas. Cada quien quiere crear un sujeto y darle un rostro según su imagen y semejanza, cada quien quiere completar la otra mitad del héroe, cada quien quisiera ser un Dios dador de vida.

Si algo tienen en común Shakespeare, Defoe, Rousseau, Simón Rodríguez, Rodó y Retamar es haber pretendido convertirse en una suerte de dioses, en gestores de vida y en creadores de metáforas humanas. Quizás esa intención sea su punto de encuentro y su lugar común en los discursos y prácticas pedagógicas de la modernidad. Tal vez la esencia del maestro esté en la gestación de su discípulo mediante la cual se crea a sí mismo.

No pretendemos cerrar este texto de modo definitivo, preferimos dejar algunas interrogaciones:

¿Los escritores, productores de cine y los maestros crean discípulos a su imagen y semejanza? ¿La recreación de héroes dejará siempre algo por escribir en el escenario pedagógico?

\footnotetext{
${ }^{14}$ Destaco que esta discusión está en el epicentro de mi tesis doctoral.

${ }^{15}$ Ver: Martínez B., A. (2004). De la escuela expansiva a la escuela competitiva.
} 


\section{Referencias bibliográficas}

Anzola, M, (2003). El antes y el después de la Misión de Robinson: Mitos y Verdades. Educere, octubre-diciembre, año/ vol. 7, número 023 , Universidad de los Andes, Mérida, Venezuela, pp. 401-406.

Blanco, R. B. (1945). Mocedades de Bolivar, Colección Libros de Revista Bohemia, Caracas: 86- 87.

Borges, J. L. (1996). Historia de la eternidad, 1936. Obras completas I, Barcelona Emecé, Editores: 412.

Defoe, D. (1816; 1919). Robinson Crusoe, traducción de Carlos Pujol. RBA Editores, Barcelona.

Fernández, R. (1991,2005). Todo Caliban, Instituto Latinoamericano de Servicios Legales Alternativos, ILSA, Bogotá.

Foucault, M. (2005) El orden del discurso.

Jouvenet, L. P. (1989). Rousseau, Pedagogía y política, Trillas, México.

Martínez Boom, A. (2004). De la escuela expansiva a la escuela competitiva. Dos modos de modernización en América Latina, Anthropos, Barcelona.

Obras escogidas de Simón Rodríguez (1985). Prólogo de Enrique Bernardo Núñez editado en 1946, Bloque de armas, Caracas: 15.

Ocampo, J. (2007) "Extracto sucinto de mi obra sobre la educación republica$n a$ ”. Presentación del documento de Simón Rodríguez, En: Revista de historia de la educación latinoamericana, Rude- colombia. No. 9, Universidad Pedagógica y Tecnológica de Colombia.

Oliveri G. (2000), En: Educere, Ideas y personajes de la educación latinoamericana y universal, año 3, No. 9, junio, 135. . (1998). Simón Rodríguez: un Revolucionario, XXIV Simposium de la literatura, Maracaibo.

Palmero. G., Elena (2005). Calibán en perspectiva: caminos de una metáfora en el discurso latinoamericano de la identidad, Islas (Santa Clara, Cuba), Universidad Central Las Villas.

Pérez, A. (2008). Simón Rodríguez, Ediciones Fe y Alegría, Caracas.

Rodó, J. E. (1900; 1947). Ariel, Sopena, Buenos Aires.

Rodríguez S. Escritos, (1954) 3 Vols. (Comp. y Estudio Bibliográfico: P. Grases; Prólogo de. Uslar Prieti), Sociedad Bolivariana de Venezuela, Caracas.

Rousseau, J. J. (1979). El contrato social, Editorial Linotipo, Bogotá .$(1762,2002)$. Emilio o la educación, Editorial Porrúa, México . (1782, 1989). Las confesiones, Garnier Hermanos, Paris

Rumazzo, A. (1975). Obras completas de Simón Rodríguez (2001), Tomo I, Venezuela, presidencia de la República, Caracas. 
Russel, B. (1978) Historia de la filosofía occidental, Tomo II, Editorial Capítulo IX, Rousseau, Espasa-Calpe, S.A., Madrid, $308-313$.

Shakespeare, W. (1612-2007). La tempestad, Traducción de Marcelo Cohen y Graciela Speranza, Buenos Aires.
Vasconcelos, J (1935; 1952). De Robinson a Odiseo. Pedagogía estructurativa, Constancia, México D.F.

Vial, F. (1937). La doctrina educativa de J.J. Rousseau, Editorial Labor, Barcelona.

\section{Consultas electrónicas}

Daniel Felipe Arranz: www.cervantesvir- Ernesto Del Gesso, Antes y después de tual.com/servlet/SirveObras/.../012918_7. Robinson Crusoe, (2007) Rosario, Arpdf., consulta realizada en julio de 2010. gentina, en http://librosenblog.com. Conwww.unavarra.es/conocer/calidad/pdf/ sulta realizada en febrero de 2009.

guiaplan. PDF 